University of Nebraska - Lincoln

DigitalCommons@University of Nebraska - Lincoln

May 1984

\title{
Differences in Survivorship, Development Rate and Fertility between the Long-winged and Wingless Morphs of the Waterstrider, Limnoporus Canaliculatus
}

Anthony J. Zera

University of Nebraska - Lincoln, azera1@unl.edu

Follow this and additional works at: https://digitalcommons.unl.edu/bioscizera

Part of the Microbiology Commons

Zera, Anthony J., "Differences in Survivorship, Development Rate and Fertility between the Long-winged and Wingless Morphs of the Waterstrider, Limnoporus Canaliculatus" (1984). Anthony Zera Publications. 20.

https://digitalcommons.unl.edu/bioscizera/20

This Article is brought to you for free and open access by the Papers in the Biological Sciences at DigitalCommons@University of Nebraska - Lincoln. It has been accepted for inclusion in Anthony Zera Publications by an authorized administrator of DigitalCommons@University of Nebraska - Lincoln. 


\title{
Differences in Survivorship, Development Rate and Fertility between the Long-winged and Wingless Morphs of the Waterstrider, Limnoporus Canaliculatus
}

\author{
Anthony J. Zera \\ Department of Ecology, and Evolution, State University of New York, Stony Brook, New York 11794 \\ (Present address: Department of Zoology, University of Texas, Austin, Texas 78712).
}

Submitted February 1983; revised March 1984.

Species of waterstriders (Gerridae: Hemiptera) exhibit a remarkable diversity in degree of winglessness (Vepsalainen, 1978; Calabrese, 1980; Zera, 1981). Some species consist exclusively of fully-winged individuals, while other species are composed almost exclusively of wingless individuals; many species exhibit the intermediate case of wing polymorphism and consist of various proportions of fully-winged, short-winged and/or wingless morphs. Wingpolymorphic species often exhibit dramatic spatial and/or temporal variation in morph ratios, both among populations of the same species and among species. Because of this diversity, waterstriders, especially wing polymorphic species, are ideal candidates for the study of the evolution of winglessness (or conversely, the evolution of dispersal). One of the major questions in the study of the evolutionary forces which influence wing polymorphism concerns fitness differences among the morphs. In many non-gerrids, dramatic differences between the fully-winged and the short-winged or functionally equivalent (Anderson, 1973) wingless morph have been documented in a variety of fitness-associated traits (for reviews, see Harrison, 1980; Dingle, 1982). These include differences in such traits as survivorship under stress, duration of larval or nymphal development, age of first reproduction, and fecundity. Moreover, one of the most important results of these studies is the demonstration that differences in fitness traits are often consistently associated with a particular morph, even in phylogenetically distant species. For example, faster development rate, higher fecundity, and earlier age of first reproduction are almost always associated with the short-winged or wingless morphs. Thus, difference in wing length is the most obvious external manifestation for difference in a diverse set of coordinated traits; these alternate sets of traits represent reproductive/sedentary versus diapause/dispersing life-history strategies (i.e., the flight-oogensis syndrome, Johnson, 1969).

In contrast to the studies mentioned above, there is little information concerning fitness differences among morphs of varying wing length in Gerrids. The only differences which have been documented are in overwintering ability between morphs of Gerris aper (Ekblom, 1941) and G. lacustris (Vepsalainen, 1974) and in the rate of development of reproductive maturity between morphs of G. lacustris (Anderson, 1973). Numerous other traits such as skating ability, various aspects of female fertility, and duration of nymphal development have been investigated in several species, but no significant morph-associated variation in these traits has been documented (Poisson, 1924; Brinkhurst, 1959; Guthrie, 1959; Anderson, 1973; Vepsalainen, 1973, 1974). However, in these studies, sample sizes were very small, and only enormous differences in these traits would have been documented (see Discussion); studies employing sample sizes which would contain sufficient statistical power to discern realistic variation in fitness among the morphs have yet to be undertaken. The lack of adequate tests of fit- 
TABLE 1. Frequency of the long-winged morph in pre- (fall) and post-overwintering (spring) populations of Limnoporus canaliculatus. See Materials and Methods for sampling dates.

\begin{tabular}{lllll}
\hline \hline & & \multicolumn{2}{c}{$\begin{array}{c}\text { Frequency of the } \\
\text { long-winged morph }\end{array}$} & \\
\cline { 2 - 3 } Population & \multicolumn{1}{c}{ Fall } & \multicolumn{1}{c}{ Spring } & Results of $x^{2}$ tests $^{\mathrm{c}}$ \\
\hline PR $^{\mathrm{a}}$ & Males & $.62(116)^{\mathrm{b}}$ & $.92(85)$ & $P<.005$ \\
& Females & $.73(102)$ & $.93(99)$ & $P<.005$ \\
PT & Males & $.39(109)$ & $.78(78)$ & $P<.005$ \\
& Females & $.58(113)$ & $.90(30)$ & $P<.005$ \\
NI & Males & $.92(119)$ & $.91(68)$ & $P>.1$, n.s. \\
& Females & $.89(122)$ & $.98(99)$ & $P<.025$ \\
NISS & Males & $.04(120)$ & $.07(122)$ & $P>.1$, n.s. \\
& Females & $.05(131)$ & $.15(101)$ & $P<.01$ \\
HALL & Males & $.47(110)$ & $.70(71)$ & $P<.005$ \\
& Females & $.45(86)$ & $.69(73)$ & $P<.005$ \\
\hline
\end{tabular}

a Localities correspond to those in Zera (1981) and Zera et al. (1983); HALL - Hall's Pond, W. Willington, CT.

b Number in parentheses is the sample size.

e Results of $x^{2}$ tests of fall versus spring morph frequencies.

ness variation among morphs of differing wing length, in turn, means that the forces influencing wing polymorphism in natural populations of gerrids remain poorly understood. This study represents the beginning of an in-depth study of adaptive differences between the fully-winged and the wingless morphs of the waterstrider, Limnoporus canaliculatus, and the biochemical/physiological bases of these differences. As will be seen below, despite the modest sample sizes employed, substantial differences in several fitness traits have been observed.

\section{MATERIALS AND METHODS}

\section{Definitions}

Wing polymorphism in gerrids consists of discontinuous variation in the length of both pairs of wings (Zera, 1981). The polymorphism may be the consequence of genetic differences between morphs (genetic polymorphism), environmental conditions under which the morphs develop (environmental polyphenism), or a combination of the two. The term polymorphism is used here with no implication as to whether morphs are genetically differentiated or are a consequence of different environmental conditions during development. The terms genetic polymorphism or environmental polyphenism are used only when it is clear that morph differentiation is a consequence of genetic or environmental variation.

\section{Species Studied}

Limnoporus canaliculatus is a semiaquatic hemipteran which occurs on the surface of ponds and streams. The distribution and life cycle of this species have previously been reported (Calabrese, 1979; Zera, 1981). Populations of $L$. canaliculatus consist of various proportions of fully-winged, wingless and (rarely) short-winged morphs and exhibit considerable spatial and temporal variation in morph frequencies (Zera, 1981; Zera et al., 1983; also see Table 1). Populations south of Massachusetts are composed almost exclusively of wingless individuals in the summer but are composed of varying proportions of winged individuals in the fall. Fall polymorphic populations of this species may exhibit dramatic spatial variation of morph frequencies. The spatial and temporal pattern of variation of morph frequencies in $L$. canaliculatus is the result of an interaction between environmental polyphenism and genetic polymorphism (Zera et al., 1983). That is, genotypes differ in their capacity to develop into a particular morph under various environmen- 
tal conditions. For example, genotype "A" will develop into a wingless morph under "summer" conditions and into a winged morph under "fall" conditions. On the other hand, genotype "B" will develop into a wingless morph under both conditions. Briefly, the life cycle of L. canaliculatus in New England (Zera, 1981) is as follows: overwintering occurs in the adult stage. In the spring (April), adults emerge, mate, lay eggs, and die shortly thereafter. The resultant progeny comprise the sedentary-reproductive summer generation. Offspring of the summer generation and possibly some offspring produced by mating of overwintered adults late in the spring emerge in late summer-fall (August-early October) in reproductive diapause and leave the water surface in mid-late October. An unknown proportion of winged individuals disperses to overwintering sites. Thus, a major feature of the life-cycle of gerrids is an alternation of a sedentary-reproductive summer generation with a diapause-dispersing fall generation. This alteration of generations strongly influences the seasonal variation of morph frequencies described above.

\section{Populations Studied}

In order to determine if morph frequency changes occurred during the overwintering period, five populations were sampled in the fall (9/29-10/5) and spring (4/29-5/15) of 19781979 , or $1981-1982$ in the case of the HALL population. The populations sampled were as follows: Pink Ravine-II (PR-II), Ct.; Petersham (PT), Mass.; Niantic (NI-II), Ct.; Nissequogue (NISS), N.Y.; and Hall's Pond (HALL), Ct. (see Table 1). All ponds are large permanent ponds. Individuals used for the development rate studies were $F_{1}$ progeny of mass mated adults which had been collected at Hall's Pond, West Willington, Connecticut on April 10, 1982. Individuals used for adult survivorship and fertility studies were field collected on October 1, 1982 from the Pink Ravine-II site, a pond which is approximately 50 yards from the Pink Ravine site (Zera, 1981). All collected individuals at this site had shrunken abdomens, a characteristic of adults in reproductive diapause; no mating was observed during the fall collection period.

\section{Development Rate Study}

Field collected individuals from the HALL population were divided into two mass mated groups: 10 winged $\widehat{\partial} \widehat{\partial} \times 10$ wingless $\phi \odot$ and 10 wingless $\hat{\partial} \widehat{\partial} \times 11$ winged $+ㅇ$. Care was taken to use only females that had greatly distended abdomens and thus were actively laying eggs. Past experience had indicated that such field-collected females did not differ greatly in egg laying ability over a short period of time. Thus one could use a mass mating design and be confident that virtually all females would be contributing some progeny and that at least $75 \%$ of the females were major contributors to the total progeny pool. Adults and deposited eggs were maintained at $22 \pm 2{ }^{\circ} \mathrm{C}, 16$ $\mathrm{h}$ light: $8 \mathrm{~h}$ dark photoperiod. Each day of the first two days of egg hatch, equal numbers of newly hatched nymphs were taken from each of the two mass rearings and were placed together in individual containers at a density of 12.5 individuals per $100 \mathrm{~cm}^{2}$ (approximately 60 nymphs in each of 6 containers). All individuals in any one container hatched on the same day. Nymphs were maintained at this density until fifth instar when, because of their much larger size, they were equally divided into two containers. Individuals were fed fruitflies and houseflies as in Zera et al. (1983) and were reared at $22 \pm 2{ }^{\circ} \mathrm{C}$ under a $16 \mathrm{~L}: 8 \mathrm{D}$ photoperiod with a decremental change of 15 minutes every second day, starting with the second day of egg hatch. A decremental change was used since winged morphs are produced in fall populations under short (i.e., $<16$ hours light) decreasing photoperiod (see Zera et al., 1983 for further discussion of this point). The first adults emerged under a $13.5 \mathrm{~L}: 10.5 \mathrm{D}$ cycle. Once adult emergence began, all containers were surveyed daily, and newly emerged adults were scored with respect to sex and morph type. Mortality during the development rate experiment was approximately $39 \%$. 


\section{Fertility and Overwintering Survivorship Experiments}

Individuals collected at the Pink Ravine- II site were kept on moist paper towels for one month at $6{ }^{\circ} \mathrm{C}$ without food prior to the fertility experiments. This was done to simulate the overwintering period and thus to provide biologically realistic conditions under which to compare fertility differences between the morphs. As mentioned above, long-winged and wingless morphs reproduce in the field in the spring after overwintering. A second reason for subjecting adults to this treatment was to assess potential differences in survivorship during the overwintering period. After the one month period without food, morph type and sex were recorded for all living and dead individuals in this treatment. Surviving individuals were used in the fertility studies. Potential biases in fertility studies using morphs that exhibited differential survivorship under laboratory simulated overwintering conditions will be dealt with below.

Differences in fertility between the winged and wingless females were measured by counting the number of fertile eggs produced by females of pair crosses each day or every other day during a 13 day period. The experiment was conducted as follows: 16 days prior to the initiation of crosses, males were removed from the $6{ }^{\circ} \mathrm{C}$ treatment and were first transferred to $15{ }^{\circ} \mathrm{C}, 12 \mathrm{~L}: 12 \mathrm{D}$ for two days and were then transferred to $20{ }^{\circ} \mathrm{C}$ 14L:10D photoperiod with an incremental change of 15 min every other day. This was done to break diapause in males before mating pairs were initiated and thus to eliminate the possibility that apparent fertility differences among females were due to differential diapause termination in males. After 12 days under these conditions, males were reproductive and attempted to mate with tester females. At this time, the winged and wingless females were removed from the 6 ${ }^{\circ} \mathrm{C}$ treatment, were kept for two days at $15^{\circ} \mathrm{C}$, 12L:12D without feeding, and were placed in- dividually in pint containers with a male and a small piece of styrofoam as a substrate for egg laying, at $20^{\circ} \mathrm{C}, 14 \mathrm{~L}: 10 \mathrm{D}$. Thirty winged and 30 wingless females were individually tested for fertility differences. Since there were not enough males to pair cross with each female, males were paired with one-half of the winged and one-half of the wingless females and were randomly transferred to the remaining females at one or two day intervals. For the first five days, males were transferred every day; after that time they were transferred every other day. Since isolated females can lay fertile eggs for up to two weeks after having mated (Zera, unpubl.), the absence of a male for one or two days was expected to have no observable effect upon female fertility. The randomization of males was done to eliminate male contributions to differences in fertility between winged and wingless females. Containers were placed on a large table and their arrangement was randomized every three days. Water was changed once a week and adults were fed one housefly per individual per day until the thirteenth day after the initiation of pair crosses (fifth day after the commencement of egg laying) after which they were fed one housefly per individual every other day. Photoperiod was increased from the initial $14 \mathrm{~L}: 10 \mathrm{D}$ as follows: $14.25 \mathrm{~L}: 9.75 \mathrm{D}$ on day $2,15.25 \mathrm{~L}: 8.75 \mathrm{D}$ on day 3, and 16L:8D on day nine post initiation of mating pairs. An increasing photoperiod was used since overwintered females begin egg-laying in the spring when photoperiod is short $(<16 \mathrm{~L})$ and increasing. Styrofoam pieces were checked daily for attached eggs. After the first day of egg laying, the styrofoam pieces were removed every day for the first 5 days of egg laying, and every other day after that point, and a new piece of styrofoam was placed in the respective containers. Styrofoam pieces were kept for $48 \mathrm{~h}$ before eggs were counted. This enabled discrimination between melanized fertile eggs and milky-white infertile eggs. 


\section{Statistical Analyses}

All statistical tests and methodologies (e.g., data transformations) described below are from Sokal and Rohlf (1981). Differences in morph frequencies of pre- versus post-overwintered field samples of $L$. canaliculatus were analyzed using $\mathrm{R} \times \mathrm{C}$ tests of independence. Overwintering survivorship in the laboratory was analyzed by a three-way test of independence using log-linear models (BIOM computer program LOGLIN; Rohlf, 1982). Development rate data was analyzed by a two-way ANOVA of pooled data from the six replicate containers after square-root transformation. There were no significant differences in mean development rate of winged or wingless morphs for either sex among replicates. Prior to using the two-way ANOVA, all distributions were tested for goodness of fit to the normal distribution by the Kolmogorov-Smirnov test and for equality of variances by Bartlett's test. There were no significant differences from normality, nor inequality of variances. Significance of fertility differences between winged and wingless females was ascertained by one-tailed sign-tests with the a priori expectation that wingless females would exhibit higher fecundity than winged females. This has been documented for many insects (Harrison, 1980; Dingle, 1982). Morph frequencies of the pre- and post-overwintered samples of five Limnoporus canaliculatus populations are given in Table 1. For females, there was a significant increase in the frequency of the long-winged morph during the overwintering period in each population. Similarly, three of five populations exhibited a significant increase in the frequency of longwinged males during this period. In most cases, morph frequency changes were substantial, often involving an increase of $40 \%$ or more. In only one case, males of the NI population, was there a decrease in the frequency of the longwinged morph during the overwintering period; the decrease was non-significant and only amounted to approximately $1 \%$. Survivor- ship data for winged and wingless $L$. canaliculatus in laboratory simulated overwintering conditions are given in Table 2. As in the field samples, winged males and females exhibited greater survivorship than wingless males or females $(G=10.80,2$ d.f., $P<.005)$. There were no significant differences in survivorship of morph types between the sexes (Table 2).

Development rates of winged and wingless males and females are given in Table 3. The wingless morph exhibited a substantially faster developmental rate than the winged morph. In addition, there was a significant sex $\times$ morph interaction. This was due to the greater reduction in development time of wingless versus long-winged females compared with wingless versus long-winged males.

In addition to the faster developmental rate, wingless females also exhibited significantly greater fertility than winged females. Table 4 lists the number of eggs laid by winged and wingless females in 1- or 2-day intervals for the first 13 days of the reproductive period. Wingless females laid a greater number of eggs than winged females on 8 of 9 days on which egglaying was recorded. This difference is statistically significant $\left(\chi^{2}=5.44,1 d\right.$.f.; $P<.025$, onetailed test). In addition to the overall greater number of eggs laid by wingless females during the entire study period, wingless females laid a substantially greater proportion of eggs in the early stages of reproduction. Wingless females contributed $60 \%$ of the total number of eggs laid during the first 5 days of reproduction (half the sample points), and $54 \%$ of the eggs laid during the remaining 8 days (Table 4 ). The difference between these two percentages is highly significant $\left(\chi^{2}=8.81,1\right.$ d.f.; $\left.P<.005\right)$.

Table 5 lists data for the number of reproductive (egg-laying) females and the number of eggs laid per reproductive female. These are two components of the difference in the total number of eggs laid between long-winged and wingless females during the 13-day period presented in Table 4. Over the 13-day period, 
TABLE 2. Differential survivorship of the longwinged and wingless morphs of Limnoporus canaliculatus under laboratory-simulated overwintering conditions. Individuals were kept at $6 \mathrm{C}$ for one month without food.

\begin{tabular}{lcrc}
\hline \hline \multirow{2}{*}{ Sex } & & \multicolumn{2}{c}{ Morph type } \\
\cline { 3 - 4 } Males & Condition & Winged & Wingless \\
\cline { 3 - 4 } Females & Alive & 27 & 48 \\
& Dead & 1 & 12 \\
& Alive & 51 & 51 \\
& Dead & 4 & 15 \\
\hline
\end{tabular}

Results of three-way $G$-tests using log-lınear models (Sokal and Rohlf, 1981)

Independence of mortality and morph type for each sex: $G=10.80$, 2 d.f; $P<.005$

Mortality $\times$ sex $\times$ morph interaction: $G=.25,1 d f$. $P>1$, n.s.

$H_{o}$ : Degree of dependence in each morph $\times$ mortality table is the same for both sexes

1) Complete independence of sex from mortality and morph type: $G=4.62,3 d . ; ; P>1$, n.s.

2) Independence of morph type and sex for both alive and dead classes: $G=4.59,2$ d. $f ; P>1$, n.s.

$H_{O}$ is not rejected; morph dependent mortality is not sex-dependent.

wingless females laid more eggs per female (i.e., exhibited greater reproductive efficiency) than long-winged females $\left(\chi^{2}=2.77 ; P<.05\right.$; one-tailed test). In addition, during this time, there were more egg-laying wingless females per sample than winged females $\left(\chi^{2}=5.44 ; P<\right.$ .025; one-tailed test).

\section{DISCUSSION}

\section{Comparison of Results with Other Laboratory Studies}

1) Survivorship under Laboratory-simulated Overwintering Conditions.-Differential survivorship between morphs of $L$. canaliculatus under laboratory-simulated overwintering conditions observed in this study is similar to results obtained for several other wing-polymorphic or flight muscle-polymorphic species. Like L. canaliculatus, the long-winged morph of the gerrid, Gerris lacustris, exhibited greater survivorship under overwintering conditions than the short-winged morph (Vepsalainen, 1974). As mentioned previously, the shortwinged and wingless morphs are functionally equivalent (Anderson, 1973). Ekblom (1941) also observed differential survivorship between morphs of $G$. asper, but the rank order of sur-
TABLE 3. Development time (days) from egg-hatch to adult eclosion for the long-winged (MAC) and wingless (APT) morphs of Limnoporus canaliculatus. Development time was measured at $22 \mathrm{C}$. See Materials and Methods for additional details.

\begin{tabular}{lccccc}
\hline \hline & \multicolumn{3}{c}{ Mean development time (days) } \\
\cline { 2 - 3 } \cline { 6 - 7 } & \multicolumn{2}{c}{ Males } & & \multicolumn{2}{c}{ Females } \\
\cline { 2 - 3 } \cline { 5 - 6 } & Winged & Wingless & & Winged & Wingless \\
\hline Mean & 25.77 & 25.05 & & 26.33 & 24.46 \\
S.E.M. & .14 & .22 & & .13 & .29 \\
Sample size & 88 & 37 & & 76 & 24 \\
\hline
\end{tabular}

\begin{tabular}{|c|c|c|c|}
\hline \multirow{2}{*}{$\begin{array}{l}\text { Source of } \\
\text { varation }\end{array}$} & \multicolumn{3}{|c|}{ Results of two-way ANOVA ${ }^{a}$} \\
\hline & d.f. & $M S$ & $F$ \\
\hline Morph & 1 & .657628 & $40.74^{* * *}$ \\
\hline Sex & 1 & .002067 & .13 n.s. \\
\hline Interaction & 1 & .119576 & $7.41^{* * *}$ \\
\hline Error & 221 & .016142 & \\
\hline
\end{tabular}

a Two-way analysis of variance was performed on square-root transformed development rate data.

*** $P<.01, * * * P<.001$.

vivorship was opposite that observed in Vepsalainen's (1974) and the present study.

Two studies have compared morph-dependent survivorship under starvation conditions in non-gerrids. Tanaka (1 976) reported a greater survivorship of the long-winged versus the short-winged cricket Pteronemobius taprobanensis, while Young (1965) reported a reduced survivorship of the morph with fully developed flight muscles in the flight muscle polymorphic corixids, Sigara scotti and S. dorsalis.

These results demonstrate that morph-dependent survivorship under stressful conditions appears to be a common feature of wing- or flight-muscle polymorphic species. However, there is no particular morph which consistently exhibits greater survivorship under these conditions; there appears to be no general tradeoff between loss of flight ability and increased survivorship under stress.

2) Development Rate.-In contrast to reduced overwintering survivorship, wingless $L$. canaliculatus exhibited a faster rate of nymphal development relative to the long-winged morph. Although a number of studies have compared development rates of various gerrid morphs (Poisson, 1924; Guthrie, 1959; Anderson, preliminary results, 1973; Vepsalainen, 
TABLE 4. Total number of eggs laid by winged and wingless females of Limnoporus canaliculatus on successive one- or two-day intervals. The experiment consisted of 30 winged and 30 wingless females.

\begin{tabular}{|c|c|c|c|}
\hline \multirow[b]{2}{*}{ Date eggs were collected ${ }^{\mathrm{a}}$} & \multicolumn{2}{|c|}{$\begin{array}{l}\text { Total number of } \\
\text { eggs laid }\end{array}$} & \multirow{2}{*}{$\begin{array}{c}\% \text { increase } \\
\text { wingless } \\
\text { winged }\end{array}$} \\
\hline & $\underset{\& Q}{W_{\text {Inged }}}$ & $\underset{\& Q}{\text { Wingless }}$ & \\
\hline $1-8$ & 0 & 0 & .00 \\
\hline 9 & 9 & 49 & 444.44 \\
\hline 10 & 41 & 45 & 9.75 \\
\hline 11 & 111 & 174 & 56.75 \\
\hline 12 & 36 & 152 & 322.22 \\
\hline 13 & 156 & 102 & -34.61 \\
\hline Sub-total, days $8-13$ & 353 & 522 & 47.87 \\
\hline 15 & 398 & 425 & 6.78 \\
\hline 17 & 439 & 567 & 29.16 \\
\hline 19 & 311 & 390 & 25.40 \\
\hline 21 & 429 & 470 & 9.55 \\
\hline Sub-total, days $15-21$ & 1,577 & 1,852 & 17.44 \\
\hline Total & 1,930 & 2,374 & 23.01 \\
\hline
\end{tabular}

a Number of days after matıng pairs were initiated. Sign test of number of days on which wingless $\$ 9$ laid more eggs than winged $\$ \&$, one-tailed test with the a priori expectation that wingless females would lay more eggs than winged females (see Matenals and Methods): $\chi^{2}=5.44, P<.025$. Contingency $\chi^{2}$ test of the total number of eggs laid by winged and wingless 89 on days $9-13$ versus 15-21: $\chi^{2}=8.81 ; P<.005$.

1973, 1974), no conclusions can be drawn from these studies. Guthrie (1959) and Poisson (1924) reported that the development rate of the short-winged morph was faster than the longwinged morph in Gerris asper and G. lacustris, respectively, similar to the results obtained in this study. However, neither author performed statistical tests on the data, and Poisson (1924) did not report sample sizes in his study (Guthrie [1959] did not report variances of his development rate data and therefore standard errors could not be computed). Neither Anderson (1973) nor Vepsalainen (1973) observed any difference in development rate between morphs of Gerris lacustris, but the tests were weak. Vepsalainen's (1973) study mainly involved interspecific comparisons, and the sample sizes of different morphs within a species were small; Anderson's results were preliminary.

The faster development rate of the wingless L. canaliculatus is consistent with data for several non-gerrids. The short-winged morph ma-
TABLE 5. Number of winged and wingless L. canaliculatus females which laid fertile eggs on individual days and the mean number of fertile eggs laid by these females. Treatments consisted of 30 females of each morph type; numbers in parentheses refer to the number of dead individuals observed on that day.

\begin{tabular}{|c|c|c|c|c|}
\hline \multirow{2}{*}{$\begin{array}{l}\text { Date eggs were } \\
\text { collected }\end{array}$} & \multicolumn{2}{|c|}{$\begin{array}{c}\text { Number of egg-laying } \\
\text { females }\end{array}$} & \multicolumn{2}{|c|}{$\begin{array}{c}\text { Avg. \# of eggs } / \mathrm{egg} \\
\text { laying female }\end{array}$} \\
\hline & Winged & Wingless & Winged & Wingless \\
\hline $12 / 12-12 / 19$ & 0 & 0 & .0 & .0 \\
\hline $12 / 20$ & 1 & 5 & 9.0 & 9.8 \\
\hline $12 / 21$ & 3 & 4 & 13.7 & 11.3 \\
\hline $12 / 22$ & 9 & 12 & 12.3 & 14.5 \\
\hline $12 / 23$ & 3 & 8 & 12.0 & 19.0 \\
\hline $12 / 24$ & 12 & 9 & 13.0 & 11.3 \\
\hline $12 / 26$ & 22 & 23 & 18.1 & 18.5 \\
\hline $12 / 28$ & $22(3)$ & 26 & 20.0 & 21.8 \\
\hline $12 / 30$ & $19(1)$ & 22 & 16.4 & 17.7 \\
\hline \multirow[t]{2}{*}{$1 / 01$} & 23 & $24(1)$ & 18.7 & 19.6 \\
\hline & & $\begin{array}{r}\chi^{2} \\
P\end{array}$ & $\begin{array}{l}=2.77 \\
<.05^{b}\end{array}$ & \\
\hline
\end{tabular}

a One-tailed sign test of the number of days on which the number of egg-laying females was greater for the wingless morph (see $\mathrm{Ma}$ terials and Methods).

$b$ One-tailed sign test of the number of days on which the average number of eggs/egg laying females was greater for the wingless versus winged morph (see Materials and Methods).

tured earlier than the long-winged morph in the leafhopper, Nilaparata lugens (Kisimoto, 1956), the grasshopper, Zonocerus variegatus (Chapman et al., 1978) and the planthoppers Doratura stylata (Waloff, 1973) and Javersella pellucida (Mochida, 1973; Waloff, 1973). Although the data are meager, it appears that faster development rate may be a general characteristic of the wingless or the short-winged morph.

3) Female Fertility.-Wingless L. canaliculatus females also exhibited substantially greater egg production than winged females during the first 13 days of reproductive life. This difference appears to be due to a combination of several factors. Wingless females were more efficient egg producers. When the total number of eggs laid in a given sample period was divided by the number of females of each morph type laying eggs, the wingless females were observed to lay more eggs per reproductive female than winged females (Table 
5). Second, since there was no mortality until the seventh sampled day $(12 / 28 / 82)$, the greater number of reproductive females in five of the first six samples (Table 5) was solely due to the faster reproductive maturity of wingless females. This was coupled with the earlier mortality of winged females. During the last three sampled days, four of the five females that died were long-winged.

As mentioned in the Materials and Methods, prior to fertility measurements, females were subjected to a one-month period of $6{ }^{\circ} \mathrm{C}$ without food. During this period there was a significant difference in mortality between the morphs (Table 2). If mortality differences are correlated with fertility differences, then the fertility difference between the two morphs may not be inherent, but may be a secondary consequence of selection during the overwintering period. Given the consistently higher fertility of the short-winged or wingless morph versus the long-winged morph in many insects, when measured under a variety of conditions (see below), this is probably not the case. However, additional experiments are required to settle this issue.

A variety of investigators have searched for, but in general have failed to find, fertility differences between morphs in other gerrids (Poisson, 1924; Brinkhurst, 1959; Anderson, 1973; Vepsalainen, 1974). However, as in the development rate studies, the sample sizes were very small, and thus these studies do not constitute adequate tests of realistic fitness differences which may be present in these species. For example, Brinkhurst (1959) found no difference between the number of eggs in long-winged and short-winged $G$. lacustris. However, sample sizes were only 48 and 36 individuals, respectively. Anderson (1 973) and Vepsalainen (1974) found no difference in the mean number of eggs laid by long-winged versus short-winged females of G. lacustris. However, their comparisons (three separate experiments) only involved 12 or fewer individuals for each morph type. Interestingly, in each of the comparisons of Vepsalainen (1974) and An- derson (1973), the short-winged morph exhibited greater fecundity than the long-winged morph. This result coupled with the significant difference in fertility in Limnoporus canaliculatus suggests that there are likely to be biologically significant differences in fertility between morphs of these species and warrants further study. The higher fecundity of the wingless or short-winged morph has been documented in many insects from several different orders (see Harrison, 1980; Dingle, 1982).

In addition to morph-dependent differences in fecundity, the short-winged or wingless morph often attains reproductive maturity faster than the fully-winged morph (Harrison, 1980; Dingle, 1982). Anderson (1973) observed that, in the field, short-winged G. lacustris attained reproductive maturity faster than the fully-winged morph. This is the only fertility difference which has previously been documented in gerrids. There is a suggestion that this may also be the case for morphs of $L$. canaliculatus (Table 5). However, the effect, if any, appears to be small, and adequate testing of this phenomenon requires further study.

\section{Extrapolation of Laboratory Studies to Natural Populations}

Each of the morph-associated traits studied in L. canaliculatus was measured under only one set of conditions, and the generality of these results is therefore unknown. However, the correspondence between faster development rate and greater fertility of the wingless (versus the long-winged) morph in this species and in many other insects, suggests that these differences may be general characteristics of the long-winged and the short-winged or wingless morphs. The variety of conditions under which these traits have been measured in the laboratory also suggests that these differences are likely to be manifest in natural populations. The difference between morphs in survival under stress also suggests that this may be a general characteristic of morphs of differing wing length. The concordance of survivorship in laboratory experiments (Table 2) with morph fre- 
quency changes in natural populations (Table 1) suggests that differential overwintering ability may be an important influence on morph frequencies in natural populations.

For several reasons, the fertility differences among morphs observed in this study are likely to be magnified in the field. As mentioned above, the difference in egg production between the long-winged and wingless morphs was significantly greater in the first half of the egg laying period. The increased difference early in reproduction may compound the overall fertility difference because of the increased probability of survivorship of early clutches due to cannibalism by older progeny on younger progeny. Cannibalism of older nymphs on younger nymphs is known to occur commonly in both laboratory and field populations of many gerrids (see references in Jarvinen and Vepsalainen, 1976). In addition, fertility differences were measured using winged females which had not flown. Roff (1977) demonstrated that flight significantly reduces egg production in Drosophila melanogaster. (For an alternate view of the influence of flight on female reproduction see Slansky, 1980). It is therefore possible that the fertility differences demonstrated between morphs in the laboratory are even greater in the field. Since dispersal flights appear to be more common in Limnoporus than Gerris ( J. Spence, pers. comm.) reduction of fertility in winged $L$. canaliculatus via flight may be more important in this species than in Gerris.

On the other hand, the differences in rate of nymphal development may not be as important in L. canaliculatus as in other gerrids which are wing polymorphic in the summer reproductive generation. In these species, differences in nymphal development rate could result in significant earlier age of first reproduction, even in the absence of any differences in rate of reproductive maturity in adults. In L. canaliculatus, however, there is an intervening overwintering period between nymphal development and adult reproduction. Thus it is difficult to envision how differences in nymphal development rates could result in differences in date of first reproduction. It is possible that the faster development of the wingless morph is simply an inherent property of the physiological mechanism of morph determination.

Since the morph-dependent differences in development rate observed in this study were documented under the same environmental conditions for both morphs, these differences could be due to inherent genetic differences between the morphs, although maternal effects cannot yet be eliminated. On the other hand, the fertility and overwintering survivorship differences were measured on field-collected individuals. Since morph determination is influenced by both genetic and environmental variables (Zera et al., 1983), it is not known to what degree these differences reflect genotype-dependent versus polyphenic-dependent differences. This is a critical question which needs to be addressed in order to begin to understand the dynamics of wing polymorphism in natural populations and which requires further study using individuals reared under controlled laboratory conditions. Such studies are currently in progress. However, it is clear from this study that, whether due to environmentally polyphenic or genetically polymorphic forms, there are substantial differences in fitness traits between the long-winged and wingless morphs of Limnoporus canaliculatus.

\section{SUMMARY}

The long-winged and wingless morphs of the waterstrider, Limnoporus canaliculatus, were compared with respect to three fitness traits: survivorship under laboratory-simulated overwintering conditions, duration of nymphal development and female fertility. The longwinged morph exhibited significantly higher survivorship under laboratory-simulated overwintering conditions, and results were consistent with dramatic changes in morph frequencies during the overwintering period in natural populations. In contrast, the wingless morph exhibited significantly faster rate of nymphal development. Wingless females also laid significantly more eggs than did long-winged females, 
and the difference was particularly pronounced during the early stages of the reproductive period. These results are consistent with studies of wing polymorphism in other insects and provide a foundation for future studies of the biochemical bases for these differences.

\section{Acknowledgments}

This study was supported by funds from an NSF Dissertation Improvement Grant in Population Biology and NSF Grant No. 1473A to Dr. Richard K. Koehn. I wish to thank David J. Innes for commenting on the manuscript. This is contribution number 487 in Ecology and Evolution at the State University of New York at Stony Brook.

\section{Literature Cited}

Anderson, N. M. 1973. Seasonal polymorphism and developmental changes in organs of flight and reproduction in bivoltine pondskaters (Hem. Gerridae). Entomol. Scand. 4: 1-20.

Brinkhurst, R. O. 1959. Alary polymorphism in the Gerroidea (Hemiptera-Heteroptera). J. Anim. Ecol. 28:211-230.

Calabrese, D. M. 1979. Pterygomorphism in $10 \mathrm{Ne}-$ artic species of Gerris. Amer. Midl. Natur. 101:6168.

1980. Zoogeography and cladistic analysis of the gerridae (Hemiptera: Heteroptera). Misc. Publ. Entomol. Soc. Amer. 11:1-119.

Chapman, R. F., A. G. Cook, G. A. Mitchell, and W. W. Page. 1978. Wing dimorphism and flight in Zonocerus variegatus (L.) (Orthoptera: Pyrgomorphidae). Bull. Entomol. Res. 68:229-242.

Dingle, H. 1982. Function of migration in the seasonal synchronization of insects. Entomol. Exp. Appl. 31:36-48.

Ekblom, T. 1941. Untersuchungen uber den Flugeldimorphismus bei Gerris asper. L. Not. Entomol. 21:49-64.

Guthrie, D. M. 1959. Polymorphism in the surface water bugs (Hemipt.-Heteropt: Gerroidea). $J$. Anim. Ecol. 28:141-152.

Harrison, R. G. 1980. Dispersal polymorphisms in insects. Ann. Rev. Ecol. Syst. 11:95-118.

Jarvinen, O., and K. Vepsalainen. 1976. Wing dimorphism as an adaptive strategy in waterstriders (Gerris). Hereditas 84:61-68.

Johnson, C. G. 1969. Migration and Dispersal of Insects by Flight. Methuen, London.
Kisimoto, R. 1956. Effect of crowding during the larval period on the determination of the wing form of an adult plant-hopper. Nature 178:641-642.

Mochida, O. 1973. The characters of two wingforms of Javesella pellucida ([F]. Homoptera: Delphacidae), with special reference to reproduction. Trans. R. Ent. Soc. London 125:177-225.

Poisson, R. 1924. Contribution a l'etude des Hemipteres aquatiques. Bull. Biol. Fr. Belg. 58: 49-305.

Roff, D. A. 1977. Dispersal in dipterans: its costs and consequences. J. Anim. Ecol. 46:443-456.

Rohlf, F. J. 1982. BIOM. A package of Statistical Programs to Accompany the text Biometry. S. Univ. N.Y. Stony Brook, N.Y. 11794.

Slansky, F., JR. 1980. Food consumption and reproduction as affected by tethered flight in female milkweed bugs (Oncopeltus fasciatus). Ent. Exp. Appl. 28:277-286.

Sokal, R. R., and F. J. Rohlf. 1981. Biometry, 2nd ed. Freeman, San Francisco.

Tanaka, S. 1976. Wing polymorphism, egg production and adult longevity in Pteronemobius taprobanensis Walker (Orthoptera, Gryllidae). Kontyu, Tokoyo 44:327-333.

Vepsalainen, K. 1973. Development rates of some Finnish Gerris Fabr. species (Het. Gerridae) in laboratory cultures. Entomol. Scand. 4:106-216.

. 1974. The life cycle and wing lengths of Finnish Gerris Fabr. species (Heteroptera, Gerridae). Acta. Zool. Finn. 141:1-73.

. 1978. Wing dimorphism and diapause in Gerris: determination and adaptive significance, $\mathrm{p}$. 218-253. In H. Dingle (ed.), Evolution of Insect Migration and Diapause. Springer-Verlag, N.Y.

Waloff, N. 1973. Dispersal by flight of leafhoppers (Auchenorrkyncha:Homoptera). J. Appl. Ecol. 10:705-730.

Young, E. C. 1965. Flight polymorphism in British Corixidae: ecological observations. J. Anim. Ecol. 34:353-389.

Zera, A. J. 198 I. Genetic structure of two species of waterstriders (Gerridae:Hemiptera) with differing degrees of winglessness. Evolution 35:218- 225.

Zera, A. J., D. I. Innes, and M. E. Saks. 1983. Genetic and environmental determinants of wing polymorphism in the waterstrider, Limnoporus canaliculatus. Evolution 37:5 13-522.

Corresponding Editor: J. A. Endler 